\title{
Study on Vibration of Hypoid gear with backlash
}

\author{
Dequan Jin'1,a, Huibin Li²,b, Huichao Gao 2,c \\ ${ }^{1}$ Foton Daimler Automotive, Beijing,China, 101400 \\ ${ }^{2}$ School of Mechanical and Vehicular Engineering, Beijing Institute of Technology, Beijing, China, \\ 100081 \\ ajindequan@bfda.cn, bhuibinli@163.com, 'gaohc@sina.com
}

Keywords: Vibration; hypoid gear; backlash; simulation

\begin{abstract}
The hypoid gear pair is a main part of driving axle and it is one of the main sources of vibration and noise in the automobile transmission. Study on mechanisms of vibration and noise of the hypoid gear pair, and investigating on reducing its vibration and noise are of great significance. Firstly, a simplified dynamic model of the hypoid gears of main reducer, with considering the time-varying teeth stiffness and teeth surface friction damping, was established. Then, on the basis of the above work, a non-linear vibration equation of the hypoid gear with the backlash was derived. Lastly, a numerical simulation method was employed to calculate different gear backlash effects on the hypoid gear vibration behaviors caused by the gear worn, and effects on the gear non-linear vibration from different work speeds of gear and different loading torques were investigated.
\end{abstract}

\section{Introduction}

The spiral bevel gear and the hypoid gear are usually used in the main reducer of automobile driving axle. The dynamic characteristics of the spiral bevel gear or the hypoid gear directly affects the smooth running and reliability of driving axle, and its dynamic characteristics research has attracted the attention of domestic and foreign scholars. A lot of achievements on linear vibration investigations and dynamic tests have been obtained. The hypoid gear pair transmission system consists of many nonlinear factors, such as time-varying mesh stiffness, transmission error, the tooth backlash and etc., which have great influences on the pair meshing stability and work reliability. Huibin Li [1], Jianping Gao [2], Zongde Fang , Jianjun Wang, Runfang Li [3-5], Kahraman A[6-14] etc. have performed a lot of theoretical and experimental studies on vibration problems from the teeth stiffness, gear backlash and eccentric quality. Their researches showed that the tooth clearances change fault vibration frequencies, and with the increase of the tooth clearances, the sub-harmonic and ultra-harmonic responses would be generated.

In this paper, a simplified dynamic model of the hypoid gears of main reducer, with considering the time-varying-teeth stiffness and teeth surface friction damping, will be established. Then, on the basis of the above work, a non-linear vibration equation of the hypoid gear with the backlash will be derived. Lastly, a numerical simulation method was employed to calculate different gear backlash effects on the hypoid gear vibration behaviors caused by the gear worn, and effects on the gear non-linear vibration from different work speeds of gear and different loading torques will also be investigated. 


\section{Vibration model for hypoid gear pair}

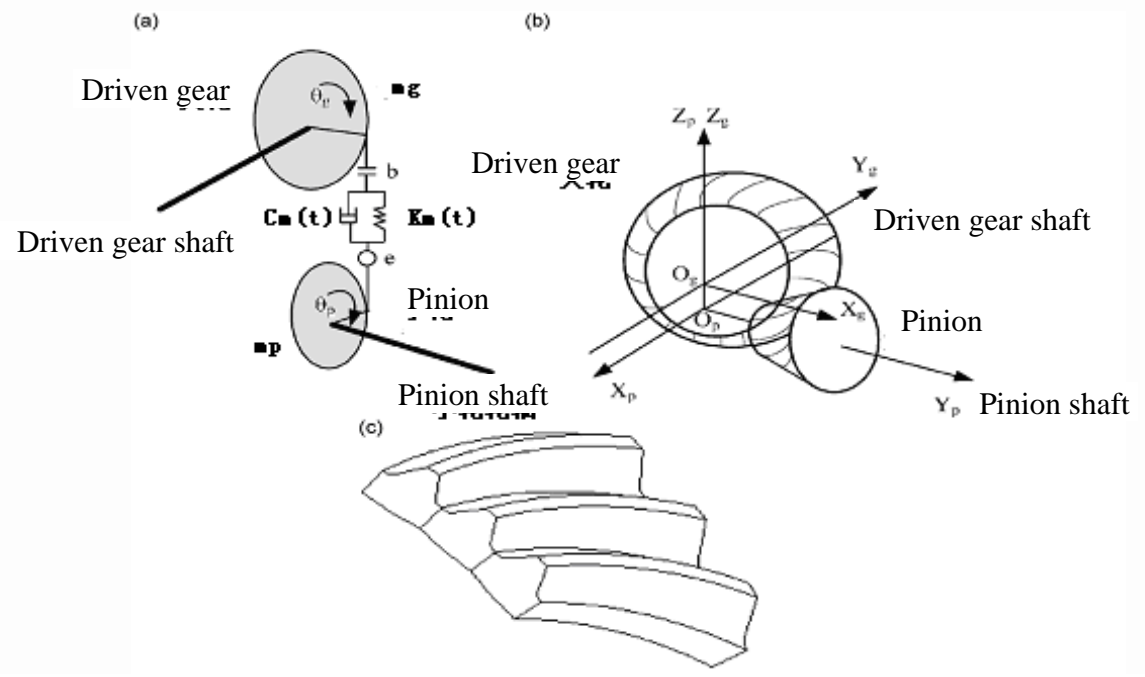

Fig. 1 A vibration model for hypoid gear pair

A hypoid gear pair, where the small gear is a driving gear, the big gear is the driven gear, and their vibration mechanics model is shown as Figure 1. Suppose the angular displacement, angular velocity, angular acceleration and rotating angular velocity of the driving gear's torsional vibration are $\theta \mathrm{p}, \dot{\theta}_{p}, \ddot{\theta}_{p}$ and $\omega \mathrm{p}$ respectively, and the angular displacement, angular velocity, angular acceleration and rotating angular velocity of the driven gear's torsional vibration are $\theta \mathrm{g}, \dot{\theta}_{g}, \ddot{\theta}_{g}$ and $\omega \mathrm{g}$ respectively. Then, $\omega \mathrm{p}=\mathrm{i} \omega \mathrm{g}$ ( $\mathrm{i}$ is transmission ratio). In Figure1, $\mathrm{km}(\mathrm{t})$-gear meshing stiffness, $\mathrm{cm}(\mathrm{t})$-gear damping coefficient, b-gear backlash, E-eccentricity, e(t)- gear composite error, Ip-moment of inertia of driving gear, Ig-moment of inertia of driven gear.

\section{Vibration equations of hypoid gear pair}

According to the analysis of force of single stage hypoid gear system with two degrees of freedom, the gear vibration differential equations can be driven:

$$
\left\{\begin{array}{l}
J_{p} \ddot{\theta}_{p}=T_{p}(t)-P_{n} \lambda_{p}-c_{m}[\dot{x}-\dot{e}(t)] \lambda_{p} \\
J_{g} \ddot{\theta}_{g}=-T_{g}(t)+P_{n} \lambda_{g}+c_{m}[\dot{x}-\dot{e}(t)] \lambda_{g}
\end{array}\right.
$$

Where

$$
\begin{aligned}
& x=\lambda_{p} \theta_{p}-\lambda_{g} \theta_{g} \\
& \dot{x}=\lambda_{p} \dot{\theta}_{p}-\lambda_{g} \dot{\theta}_{g} \\
& \dot{e}(t)=-\sum_{n=1}^{\infty} n \omega e_{n} \sin \left(n \omega t+\varphi_{n}\right) \\
& \lambda_{p}=\vec{n}_{p} \cdot\left(\vec{j}_{p} \times \vec{r}_{p}\right), \lambda_{\mathrm{g}}=\overrightarrow{\mathrm{n}}_{\mathrm{g}} \cdot\left(\vec{r}_{\mathrm{g}} \times \overrightarrow{\mathrm{j}}_{\mathrm{g}}\right)
\end{aligned}
$$

In above equations, $\vec{r}_{p}$ and $\vec{r}_{g}$ are meshing point position vectors, $\vec{n}_{p}$ and $\vec{n}_{g}$ are normal unit vectors at meshing points, $\vec{j}_{p}$ and $\vec{j}_{g}$ are unit vectors along driving gear shaft and driven gear shaft respectively.

Obviously, due to the coefficients of $\theta, \dot{\theta}$ and $\ddot{\theta}$ related to time-varying stiffness km(t),nonlinear function $\mathrm{f}(\mathrm{t})$, equations(2.1) are nonlinear time-varying equations.

\section{Numerical solutions for vibration equations}

If only considering gear backlash, then equations can be simplified as following: 


$$
\left\{\begin{array}{l}
J_{\mathrm{p}} \ddot{\theta}_{p}+P_{n} \lambda_{\mathrm{p}}+c_{m}[\dot{x}-\dot{\mathrm{e}}(t)] \lambda_{\mathrm{p}}=T_{p} \\
J_{\mathrm{g}} \ddot{\theta}_{g}-P_{n} \lambda_{\mathrm{g}}-\mathrm{c}_{\mathrm{m}}[\dot{x}-\dot{\mathrm{e}}(\mathrm{t})] \lambda_{\mathrm{g}}=-T_{g}(t)
\end{array}\right.
$$

As equations ( 2 ) are nonlinear time-varying, their theoretical solutions are difficult to be obtained. The numerical solutions are employed. For the convenience of calculation, the equations (2) are transformed into the state space, and the equations (2) are expressed as : $\dot{Z}_{i}=f_{i}\left(Z_{1}, Z_{2}, Z_{3}, Z_{4}\right), i=1,2,3,4$. Then the original equations can be expressed as:

$$
\left\{\begin{array}{l}
Z_{1}=\theta_{p} \\
\dot{Z}_{1}=Z_{2} \\
\dot{Z}_{2}=\left\{T_{p}-k_{m}(t) f\left(\lambda_{p} Z_{1}-\lambda_{g} Z_{3}-e(t)\right) \lambda_{p}-c_{m}(t)\left(\lambda_{p} Z_{2}-\lambda_{g} Z_{4}-\dot{e}(t)\right) \lambda_{p}\right\} / J_{p} \\
Z_{3}=\theta_{q} \\
\dot{Z}_{3}=Z_{4} \\
\dot{Z}_{4}=\left\{-T_{q}+k_{m}(t) f\left(\lambda_{p} Z_{1}-\lambda_{g} Z_{3}-e(t)\right) \lambda_{q}+c_{m}(t)\left(\lambda_{p} Z_{2}-\lambda_{g} Z_{4}-\dot{e}(t)\right) \lambda_{q}\right\} / J_{q}
\end{array}\right.
$$

Numerical solutions of the equations (3) are obtained by using four orders of the classical Runge-Kutta method or four orders of Runge-Kutta-Gill method, and the torsional vibration response of the hypoid gear pair can be obtained. Table 1 is the parameters of hypoid gear pair for calculation.

Table 1 The main parameters of hypoid gear pair for calculation

\begin{tabular}{lc}
\hline \multicolumn{1}{c}{ Parameters } & values \\
\hline Big endian modulus & $m=3.953 \mathrm{~mm}$ \\
Number of teeth & $Z_{1}=9, \quad Z_{2}=43$ \\
Offset distance & $\mathrm{E}=30.000 \mathrm{~mm}$ \\
Pitch circle radius & $r_{1}=20.823 \mathrm{~mm}, r_{2}=72.382 \mathrm{~mm}$ \\
Torque & $T_{\mathrm{p}}=284 \mathrm{Nm}, T_{\mathrm{g}}=679 \mathrm{Nm}$ \\
Teeth width & $b_{1}=31.99 \mathrm{~mm}, \quad b_{2}=26.00 \mathrm{~mm}$ \\
Equivalent mass of gear & $m_{1}=0.293 \mathrm{~kg}, m_{2}=1.216 \mathrm{~kg}$ \\
Moment of inertia & $J_{D 1}=0.0005 \mathrm{kgm}^{2}, J_{D 2}=0.0125 \mathrm{kgm}^{2}$ \\
Rotating speed of driving gear & $n=1311-3686 \mathrm{rpm}$ \\
Backlash & $\mathrm{b}=0 \sim 1.000 \mathrm{~mm}$ \\
\hline
\end{tabular}

During simulations, different combinations of the backlash, gear rotating speed, torque (shown in Figure 2 and Figure 3) and teeth error of the gear pair are considered, and the calculation results are shown in Figure 4 to Figure 9.

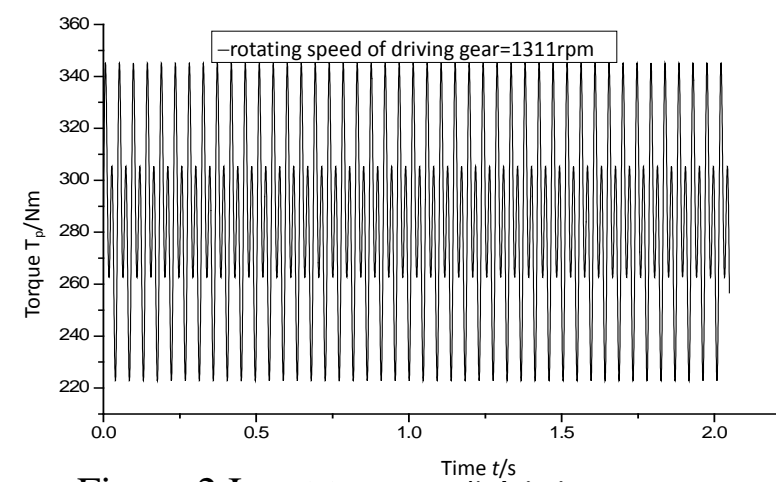

Figure 2 Input torque of driving gear

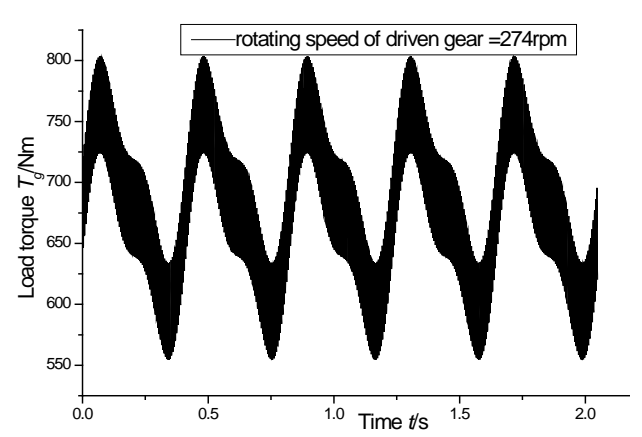

Figure 3 Load torque of driven gear 


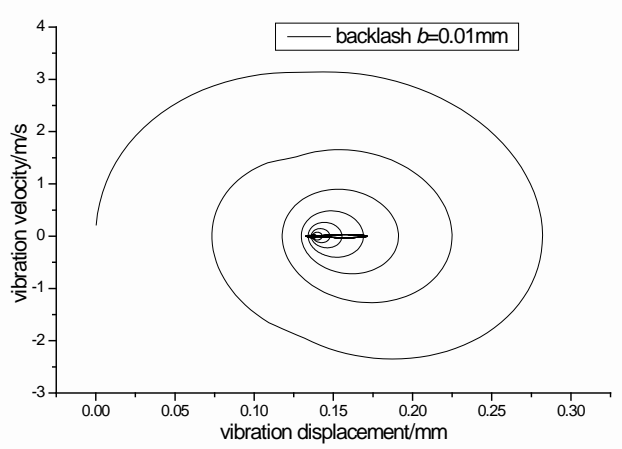

Figure 4 Phase plane diagram of vibration $\left(\mathrm{n}=1311 \mathrm{rpm}, T_{\mathrm{p}}=284 \mathrm{Nm}, \mathrm{b}=0.01 \mathrm{~mm}\right)$

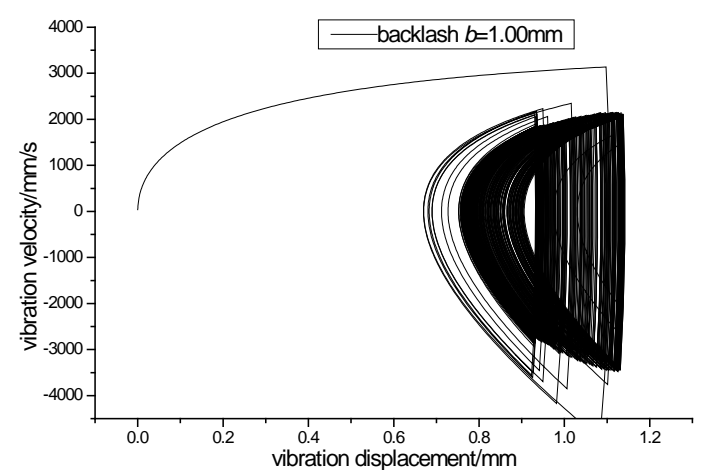

Figure 6 Phase plane diagram of vibration $\left(\mathrm{n}=1311 \mathrm{rpm}, T_{\mathrm{p}}=284 \mathrm{Nm}, \mathrm{b}=1.0 \mathrm{~mm}\right)$

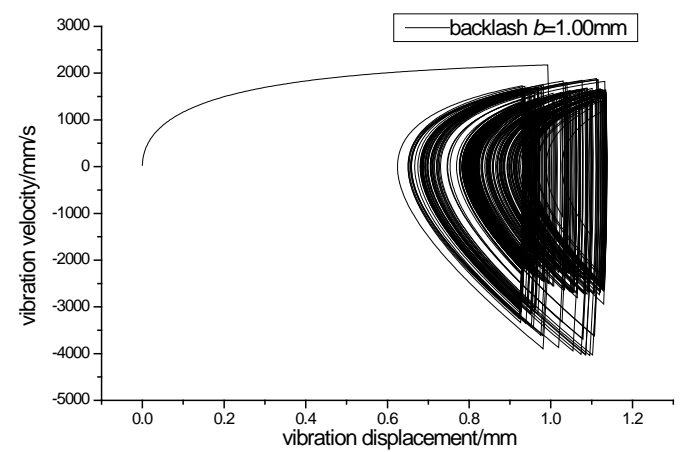

Figure 8 Phase plane diagram of vibration $\left(\mathrm{n}=2304 \mathrm{rpm}, T_{\mathrm{p}}=153 \mathrm{Nm}, \mathrm{b}=1.0 \mathrm{~mm}\right)$

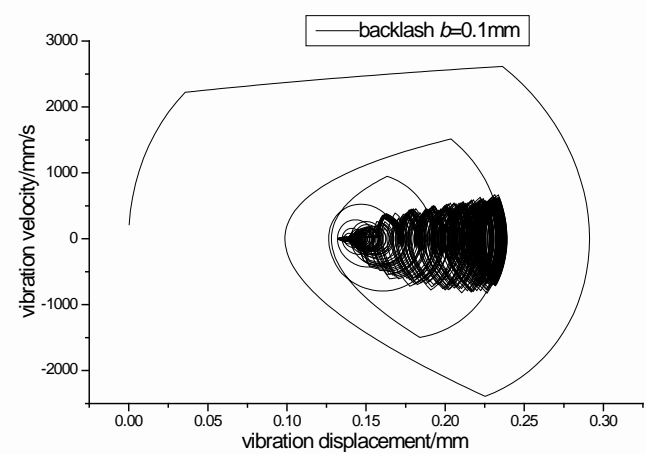

Figure 5 Phase plane diagram of vibration $\left(\mathrm{n}=1311 \mathrm{rpm}, T_{\mathrm{p}}=284 \mathrm{Nm}, \mathrm{b}=0.1 \mathrm{~mm}\right)$

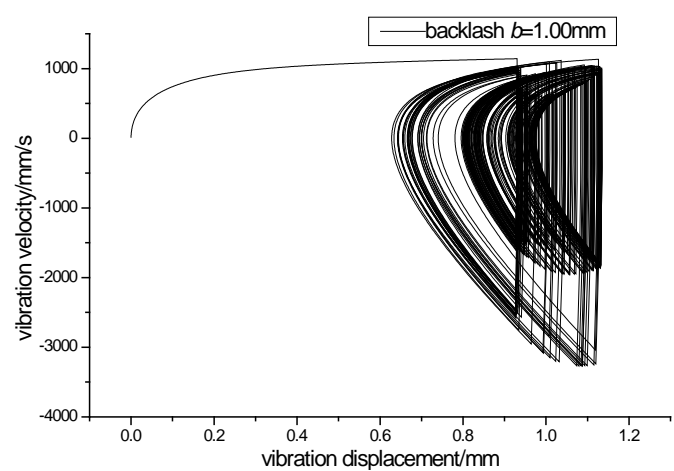

Figure 7 Phase plane diagram of vibration $\left(\mathrm{n}=2304 \mathrm{rpm}, T_{\mathrm{p}}=76.5 \mathrm{Nm}, \mathrm{b}=1.0 \mathrm{~mm}\right)$

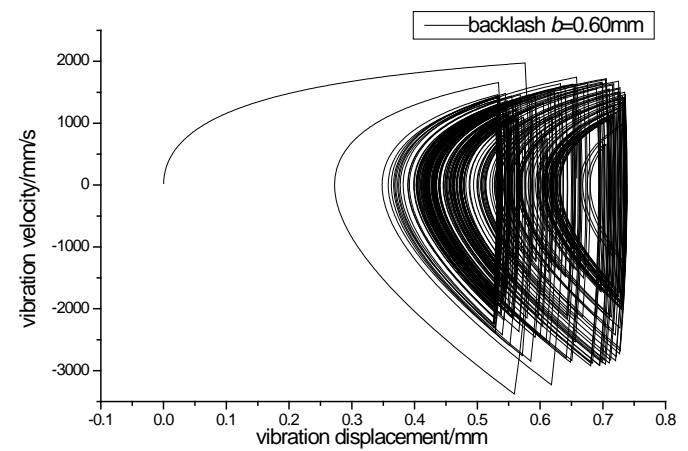

Figure 9 Phase plane diagram of vibration $\left(\mathrm{n}=3686 \mathrm{rpm}, T_{\mathrm{p}}=96 \mathrm{Nm}, \mathrm{b}=0.60 \mathrm{~mm}\right)$

According to the simulation results, we can find that when the gear tooth wear is small, the vibration phase trace closes to an ellipse. While the gear is in the moderate wear, the tooth side clearance of gear tooth is larger, and the relative vibration velocity waveform changes a lot. At the same time, gear vibration velocity rises sharply, and there is the emergence of beat vibration. Phase traces oscillate among multiple horn type curves, and vibration bifurcation appears.

When the gear tooth wears much severely, the relative displacement amplitude of gear teeth changes little and its vibration frequency spectrum characteristics also changes slightly, but the spectrum characteristics of vibration velocity changes significantly. Under such a situation, the beat vibration appears, phase trace oscillates among multiple horn type curves, and the vibration belongs to the bifurcation and chaos.

\section{Conclusion}

(1) While the gear working speed and load unchanged, the changes of backlash have effects on the vibration displacement and vibration velocity at fault frequencies of the gear. When the gear 
wear is intensified, then the tooth backlash increases. This means the change of tooth stiffness that result in the change of vibration displacement and vibration velocity amplitude. Under such a situation, the beat vibration appears, phase trace oscillates among multiple horn type curves, and the vibration belongs to the bifurcation and chaos.

(2) While considering the gear backlash, the changes of the working speed have great influence on the vibration velocity of gear at those fault frequencies. The higher working speeds, the more obvious vibration velocity amplitude at fault vibration frequencies.

(3)When considering the gear backlash, the changes of working load amplitude have small influence on both gear vibration frequencies and the amplitudes of the vibration velocity.

\section{References}

[1] Huibin Li. Reports on optimization analysis of the commercial vehicle driving system for Chongqing Changan Automobile Company (in Chinese). Beijing Institute of Technology, 2012.

[2] GAO Jian-ping, FANG Zong-de, YANG Hong-bin. Dynamic analysis of spur gear pairs with time-varying mesh stiffness and clearance non-linearity (in Chinese). ACTA AERONAUTICA ET ASTRONAUTICA SINICA, 1999,20(5):440-443.

[3] Runfang Li, Jianjun Wang. Gear System Dynamics (in Chinese). Science Publishing Company,1997.

[4] Ozguven H N, Houser D R. Mathematical models used in gear dynamics-a review. JOURNAL OF SOUND AND VIBRATION,1988,(03):383-411.

[5] Wang Sanmin, Shen Yunwen, Dong Haijun. Non-linear dynamical characteristics of a spiral bevel gear system with backlash and time-varying stiffness. CHINESE JOURNAL OF MECHANICAL ENGINEERING,2003,(2):28-32.

[6] Yang D C H,Lin J Y. Herztian damping, tooth friction and bending elasticity in gear impact dynamics.ASME Journal of Mechanisms Transmissions and Automations in Design,1987. 189-196.

[7] Blankenship G W,Singh R. A new gear mesh interface dynamic model to predict multidimensional force coupling and excitation.Mechanism and Machine Theory,1995,(01):43-57.

[8] Blankenship G W,Singh R. Dynamic force transmissibility in helical gear pairs. MechanismMachine Theory,1995,(03):323-339.

[9] Kahraman A. Dynamic analysis of a multi-mesh helical gear train.ASME Journal of Mechanical Design,1994.706-712.

[10] Kahraman A,Singh R. Non-linear dynamics of a geared rotor-bearing system with multiple clearance.Journal of Sound and Vibration,1991,(03):469-506.

[11] Raghothama A,Narayanan S. Bifurcation and chaos in geared rotor bearing system by incremental harmonic balance method.Journal of Sound and Vibration,1999,(03):469-492.

[12] Seyranian A P,Solem F,Pedersen P. Multi-parameter linear periodic systems: sensitivity analysis and applications.Journal of Sound and Vibration,2000,(01):89-111.

[13] Kahraman A,Blankenship G W. Gear dynamics experiments part-III: effect of involute tip relief.San Diego, California,1996.

[14] Kahraman A,Blankenship G W. Effect of involute contact ratio on spur gear dynamics. ASME Journal of Mechanical Design,1999,(1):112-118. 